\title{
Efeito da velocidade de resfriamento sobre a transformação da austenita em aço baixa liga
}

\section{Effect of cooling rate on the austenite transformation in low-alloy steel}

\author{
Evaldo Diniz Dias ${ }^{1}$ \\ Célio de Jesus Marcelo ${ }^{2}$ \\ Horacio Guimarães Delgado Junior ${ }^{3}$ \\ José Adilson de Castro ${ }^{4}$ \\ Carlos Roberto Xavier ${ }^{5}$
}

1 UniFOA - Graduação em Engenharia Mecânica
2 Técnico de Laboratório - Universidade Federal Fluminense
3 Professor (D.Sc.) - UERJ/UniFOA (Curso de Engenharia Civil)
4 Professor (Ph.D.) - Universidade Federal Fluminense
5 Professor (D.Sc.) - UniFOA (Curso de Engenharia Mecânica); carlos.xavier@foa.org.br

\section{Resumo}

Neste trabalho, um aço comercial baixa liga experimentou variadas velocidades de resfriamento após a sua completa austenitização, o que influenciou de forma qualitativa e quantitativa a microestrutura resultante. Para esse fim, foram exploradas as facilidades oferecidas pelo ensaio Jominy ao possibilitar o registro dos ciclos térmicos em diferentes posições do corpo de prova do aço. As microestruturas próximas às posições das temperaturas monitoradas utilizando termopares foram então caracterizadas, utilizandose um conjunto de técnicas de análise como Microscopia Óptica (MO), Microscopia Eletrônica de Varredura (MEV) e ensaio de microdureza, sendo, posteriormente, confrontadas com aquelas previstas por um diagrama de transformação durante o resfriamento contínuo. Adicionalmente, análises de imagem permitiram quantificar a fração volumétrica dos microconstituintes presentes na microestrutura do aço estudado, sendo que a fração volumétrica de martensita foi também estimada por meio da equação cinética de Koistinen-Marburger".

\section{Palavras-chave}

Aço baixa liga; austenita; resfriamento contínuo; microestrutura; ensaio Jominy.

\begin{abstract}
In this work, a commercial low-alloy steel has experimented varied thermal cycles, which have influenced on the resultant microstructure depending on the cooling rates reached. Microstructures near the temperatures monitored by thermocouples were then characterized using a group of analysis techniques, such as Light Optical Microscopy (LOM), Scanning Electron Microscopy (SEM) and microhardness testing and compared to those predicted by a continuous cooling transformation diagram. Furthermore, image analysis allowed to quantify the volume fraction of microconstituents, while the volume fraction of martensite was also estimated by the KoistinenMarburger kinetic equation".
\end{abstract}

\section{Keywords}

Low-alloy steel; austenite; cooling rate; microstructure; Jominy test.

\section{Como você deve citar?}

XAVIER, Carlos Roberto et al. Efeito da velocidade de resfriamento sobre a transformação da austenita em aço baixa liga. Cadernos UniFOA, Volta Redonda, n. 26, p. 37-45, dez. 2014. 


\section{INTRODUÇÃO}

Neste trabalho foi utilizado o aço AISI 4340 para se avaliar o efeito de diferentes velocidades de resfriamento sobre as mudanças microestruturais que ocorrem quando aços de baixa liga são resfriados após aquecimento até a sua completa austenitização. 0 aço AISI 4340 é um aço martensítico de baixa liga amplamente utilizado e que possui uma combinação de alta resistência mecânica, ductilidade e tenacidade e cujas aplicações envolvem projetos de engenharia nas áreas industrial e militar, como aeronáutica e marinha, onde elevadas propriedades mecânicas são requeridas' ${ }^{1}$ Para atingir altos níveis de desempenho, como aqueles requeridos para aplicação na indústria aeroespacial, são necessários elevados índices de resistência e de dureza, além de uma satisfatória tenacidade dos aços utilizados, sendo que uma variedade de tratamentos térmicos deve ser levada em consideração para se alcançar essa combinação de propriedades, podendo incluir, inclusive, técnicas de endurecimento superficial ${ }^{2}$. Dessa forma, é bastante útil um conhecimento prévio sobre o comportamento metalúrgico desse e de outros aços em resposta a um procedimento que envolva transformação de fases a partir de processos térmicos.

Segundo Lee e $\mathrm{Su}^{3}$, existem várias estruturas que são bastante conhecidas nos aços, tais como a ferrita/perlita, a bainita, a martensita e a austenita, com cada uma delas apresentando diferentes propriedades mecânicas. As fases e constituintes, bem como as suas quantidades e morfologia que podem ocorrer durante o resfriamento do aço avaliado a partir da sua região austenítica, dependem fundamentalmente, entre outros fatores, das velocidades de resfriamento alcançadas durante esse processo.

Estritamente falando, a martensita é a estrutura que confere a maior resistência ao aço, mas raramente é usada nessa condição, devido ao grande nível de tensões internas que estão associadas ao processo de transformação e que tornam o material extremamente frágil. A morfologia apresentada pela martensita depende do teor de carbono do aço. Em aços baixo-carbono, a martensita se apresenta na forma de ripa, agrupada em grandes pacotes ou feixes, com sua subestrutura composta por alta densidade de discordâncias e organizada na forma de células. Nos aços alto-carbono, com a temperatura $M_{s}$ situada abaixo da temperatura ambiente, a martensita se apresenta na forma de placa, consistindo de maclas muito finas, enquanto que, no caso de aços com médio teor de carbono, a situação se torna mais complexa, desde que uma mistura de martensita tipo ripa e placa pode ser encontrada ${ }^{3}$.

Por outro lado, elevados níveis de resistência para o aço aliados, ainda, a uma boa tenacidade e ductilidade podem ser conferidos pela bainita ${ }^{4}$. A microestrutura bainítica consiste de finas placas de ferrita que crescem de forma agrupada em forma de feixes, sendo que o tipo e as propriedades da bainita formada dependem de inúmeros fatores, podendo se mencionar a espessura dessas placas, bem como da morfologia e da distribuição dos carbonetos presentes e até da densidade de discordâncias na estrutura ${ }^{4,5}$. A bainita formada em temperaturas mais elevadas, também denominada bainita superior, consiste de agulhas ou ripas de ferrita que crescem para dentro da austenita em uma forma similar à estrutura Widmanstätten, com a cementita precipitada entre elas. Quando a transformação ocorre em temperaturas mais baixas, a morfologia da bainita modifica de ripas para placas com a dispersão dos carbonetos, tornando-se muito mais fina, sendo essa nova forma morfológica, geralmente, denominada bainita inferior, a qual se assemelha à martensita revenida ${ }^{6}$.

A perlita é um produto da reação eutetóide que ocorre nos aços resfriados abaixo da temperatura $A_{1}$, na qual a composição da austenita se estabelece em torno de $0,8 \%$ de carbono. A perlita corresponde a uma estrutura lamelar de cementita dispersa em ferrita, sendo que essas últimas se formam em contato direto com a austenita ${ }^{6}$.

Devido à sua importância tecnológica, a transformação austenita-ferrita tem sido amplamente investigada, desde que isso esteja relacionado com o controle e a adequação das propriedades dos 
aços $^{7}$. Em pequenos subresfriamentos abaixo da temperatura $A_{3^{\prime}}$ a ferrita nucleia nos contornos de grãos da austenita, dando origem à ferrita alotriomórfica de contorno de grão, enquanto que, em maiores subresfriamentos, existe uma tendência preferencial para que o crescimento da ferrita ocorra a partir dos contornos de grãos na forma de placas, assumindo a morfologia Widmanstätten e tornando-se mais fina, quando o subresfriamento aumenta. Dessa forma, a morfologia final da ferrita que será obtida nas transformações que ocorrem no resfriamento contínuo, podendo mencionar aquelas provenientes de tratamentos térmicos, será dependente das velocidades de resfriamento alcançadas durante esse procedimento ${ }^{6}$.

O objetivo do presente trabalho foi o de avaliar a influência da velocidade de resfriamento sobre a transformação da austenita em aço baixa liga.

\section{MATERIAIS E MÉTODOS}

\subsection{Materiais}

A composição química do aço AISI 4340 pode ser encontrada na Tabela 1.

Tabela 1 - Composição química do aço AISI 4340 (\% em peso)

\begin{tabular}{cccccccccc}
\hline $\mathbf{C}$ & $\mathbf{S i}$ & $\mathbf{M n}$ & $\mathbf{M o}$ & $\mathbf{N i}$ & $\mathbf{P}$ & $\mathbf{S}$ & $\mathbf{C r}$ & $\mathbf{C u}$ & Al \\
\hline 0,363 & 0,25 & 0,689 & 0,20 & 1,827 & 0,013 & 0,008 & 0,781 & 0,11 & 0,003 \\
\hline \multicolumn{10}{c}{ Fonte: dos autores, 2014.} \\
\end{tabular}

\subsection{Procedimento experimental}

Na Figura 1 pode ser visto o aparato experimental Jominy e os detalhes do procedimento utilizado no desenvolvimento do presente trabalho. $\mathrm{O}$ aparato Jominy ofereceu as características ideais para esse fim ao permitir que, por meio de um único experimento, vários planos do mesmo corpo de prova pudessem experimentar diferentes velocidades de resfriamento a partir da temperatura de austenitização do aço AISI 4340. 
Figura 1. Aparato experimental Jominy e procedimento para monitoração da temperatura do corpo de prova com múltiplos termopares.

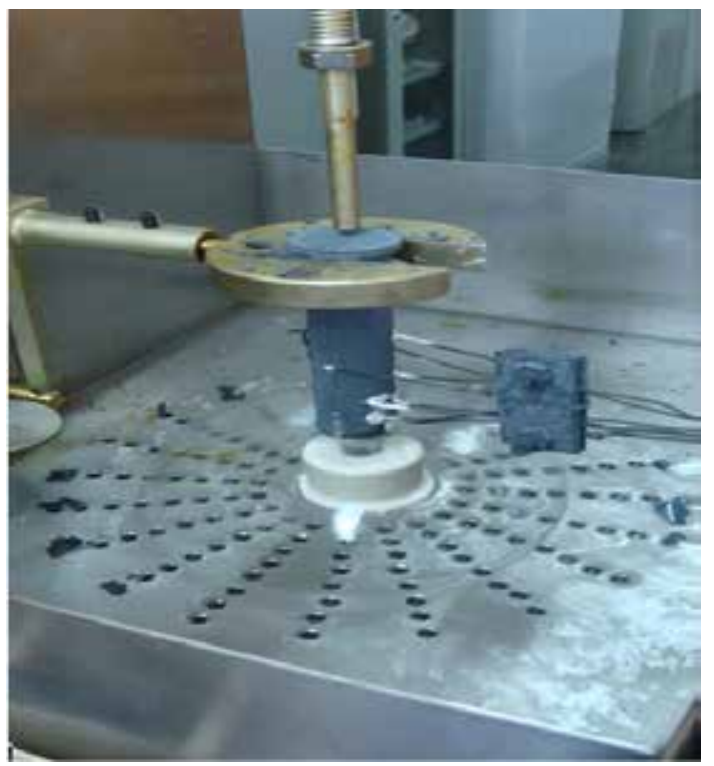

Fonte: dos autores, 2014.

Dessa forma, o corpo de prova foi fabricado segundo a norma ABNT $6339 / 89^{8}$ para determinação da temperabilidade Jominy e adaptado com orifícios para recebimento dos termopares efetuados ao longo do mesmo, conforme disposição apresentada na Figura 2. Os termopares estavam conectados a uma unidade de aquisição de dados para registro da variação da temperatura com o tempo durante o procedimento de aquecimento e resfriamento do corpo de prova.

Figura 2 - Corpo de prova Jominy e distribuição dos orifícios para recebimento dos termopares.

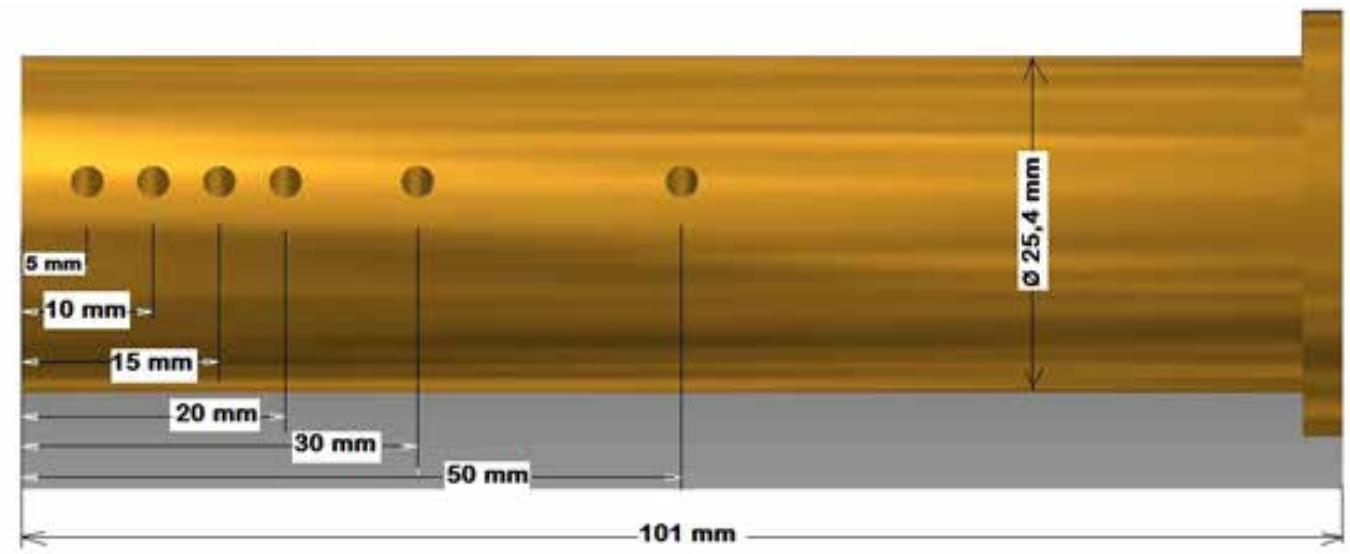

Fonte: dos autores, 2014.

Com os termopares inseridos nos orifícios, o corpo de prova foi aquecido até a sua completa austenitização em um forno tipo mufla e rapidamente resfriado em água, conforme é realizado no procedimento Jominy (Figura 1). 0 corpo de prova foi então seccionado para confecção de amostras, tomando como referência a localização dos orifícios onde foram inseridos os termopares (Figura 2). 0 objetivo foi a de que as amostras destinadas à análise metalográfica estivessem mais próximas possíveis dos planos, onde foi feito o monitoramento térmico do corpo de prova. 


\subsection{Microscopia Óptica - MO}

Como parte dos preparativos para a realização da análise microestrutural com o microscópio óptico ZEISS (CSN), as amostras foram embutidas em resinas e lixadas sequencialmente com lixas de carboneto de silício de 100, 200 400,600 e 1200 mesh, com posterior polimento, utilizando-se pasta de alumina de 6, 3, 1 e 0,05 $\mu \mathrm{m}$. A análise para quantificação dos microconstituintes presentes foi realizada com o auxílio do programa de análise de imagens "Image $\mathrm{J}$ ".

\subsection{Microscopia Eletrônica de Varredura - MEV}

As amostras foram novamente polidas e atacadas com o reagente químico nital a $3 \%$, com o objetivo de realizar a caracterização microestrutural por meio da técnica de elétrons secundários, utilizando-se, para esse fim, o Microscópio Eletrônico de Varredura FEI QUANTA 3D FEG (CSN).

\subsection{Ensaio de dureza por microindentação (HV)}

Adicionalmente, foi realizado o ensaio de dureza por microindentação com a finalidade de auxiliar na caracterização microestrutural das amostras, utilizando-se o Microdurômetro Buehler Micromet 3 (CSN) e uma carga de $25 \mathrm{~g}$.

\section{RESULTADOS E DISCUSSÃO}

Pode ser visto na Figura 3 o diagrama de transformação durante o resfriamento continuo do aço AISI 4340, juntamente com as curvas de resfriamento, as quais foram obtidas ao se registrar os dados com o auxílio dos respectivos termopares, a partir de uma temperatura, na qual esse material se encontrava totalmente austenitizado. As denominações utilizadas T1, T2, T3, T4, T5 e T6 correspondem, respectivamente, às posições dos orifícios em 5, 10, 15, 20, 30 e $50 \mathrm{~mm}$, que foram construídos ao longo do corpo de prova e onde os termopares foram inseridos (Figura 2). De acordo com a Figura 3, os únicos microconstituintes previstos pelas velocidades de resfriamento alcançadas para o aço AISI 4340 foram bainita e martensita.

Figura 3 - Diagrama de transformação durante o resfriamento contínuo do aço AISI 4340 com a superposição das curvas de resfriamento.

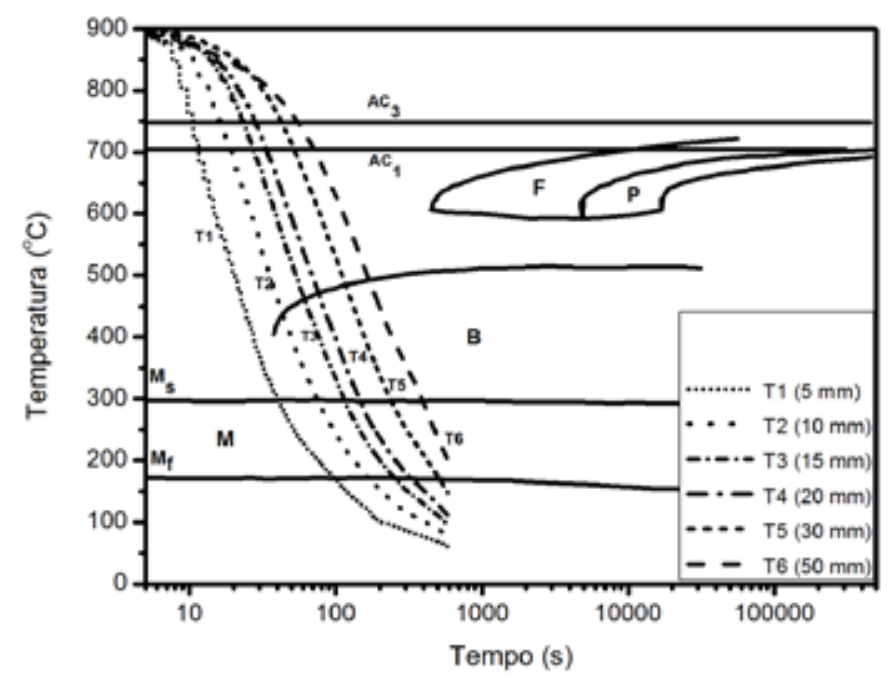

Fonte: dos autores, 2014. 
Segundo Koistinen e Marburger ${ }^{9}$, a fração $f_{M}$ de martensita que se forma em aços carbono depende da diferença entre a temperatura de início de sua transformação $M_{s}$ e a mais baixa temperatura de têmpera $T$, que é atingida durante o resfriamento, podendo ser descrita através da Equação 1.

$$
f_{M}=1-\exp \left[-0,011\left(M_{s}-T\right)\right.
$$

$\mathrm{Na}$ Tabela 2, são informados os microconstituintes que foram encontrados através do exame metalográfico nas amostras correspondentes a cada posição avaliada do corpo de prova, bem como as suas frações volumétricas médias, sendo que as frações volumétricas de martensita foram comparadas, ainda, com aquelas previstas teoricamente pela Equação 1, a qual usou os dados de temperatura registrados durante o experimento para se efetuar os cálculos.

Tabela 2 - Fração volumétrica (\%) dos microconstituintes

\begin{tabular}{|c|c|c|c|c|}
\hline \multirow[b]{2}{*}{ Posição } & \multicolumn{2}{|c|}{ Metalografia } & \multirow{2}{*}{$\begin{array}{l}\text { Equação } 1 \\
\text { Martensita }\end{array}$} & \multirow{2}{*}{$\begin{array}{c}\text { Diferença } \\
\text { Martensita (\%) }\end{array}$} \\
\hline & Bainita & Martensita & & \\
\hline $\mathrm{T} 1$ & 11 & 89 & 83 & 7,2 \\
\hline $\mathrm{T} 2$ & 13 & 87 & 80 & 8,7 \\
\hline T3 & 17 & 83 & 78 & 6,4 \\
\hline $\mathrm{T} 4$ & 23 & 77 & 77 & 0 \\
\hline T5 & 27 & 73 & 76 & $-3,9$ \\
\hline T6 & 38 & 62 & 68 & $-8,8$ \\
\hline
\end{tabular}

Fonte: dos autores, 2014.

Somente os microconstituintes bainita e martensita foram identificados nas amostras avaliadas metalograficamente contando, ainda, que as frações volumétricas de martensita apresentaram uma significativa concordância com aquelas previstas pela Equação 1 (Tabela 2).

Usando MO e MEV para caraterização, as microestruturas representativas de algumas posições monitoradas do corpo de prova podem ser vistas na Figura 4. Somente bainita e martensita foram observadas nas posições $\mathrm{T1}$, T4 e T6, o que também aconteceu nas posições restantes, entretanto as frações volumétricas de bainita aumentaram quando as velocidades de resfriamento diminuíram, confirmando o comportamento previsto pela Figura 3. Enquanto isso, a Tabela 3 apresenta os resultados médios das durezas dos microconstituintes encontrados nas amostras avaliadas. Com exceção do Termopar 6 (T6), que apresentou um ligeiro aumento, os valores correspondentes à dureza da bainita foram sempre decrescentes, quando menores velocidades de resfriamento foram registradas, podendo esse comportamento ser justificado por um aumento comparativo do teor da bainita superior na microestrutura resultante em relação à bainita inferior, sendo que, detalhes da microestrutura bainítica, obtidos via MEV, podem ser vistos na Figura 4. Em relação à dureza da martensita, pouca variação foi observada, sendo bastante coerente esse resultado já que a dureza deste microconstituinte depende, principalmente, do teor de carbono do aço. 
Tabela 3 - Dureza do microconstituinte (HV)

\begin{tabular}{ccccccc}
\hline \multirow{2}{*}{ Microconstituinte } & \multicolumn{9}{c}{ Posição } \\
\cline { 2 - 7 } & T1 & T2 & T3 & T4 & T5 & T6 \\
\hline Bainita & $*$ & 562 & 477 & 380 & 356 & 367 \\
\hline Martensita & 763 & 748 & 769 & 760 & 735 & 749 \\
\hline
\end{tabular}

* Não foi possível efetuar a medição por falta de área disponível para o ensaio.

Fonte: dos autores, 2014.

Figura 4 - a) MO: bainita e martensita e b) MEV: bainita

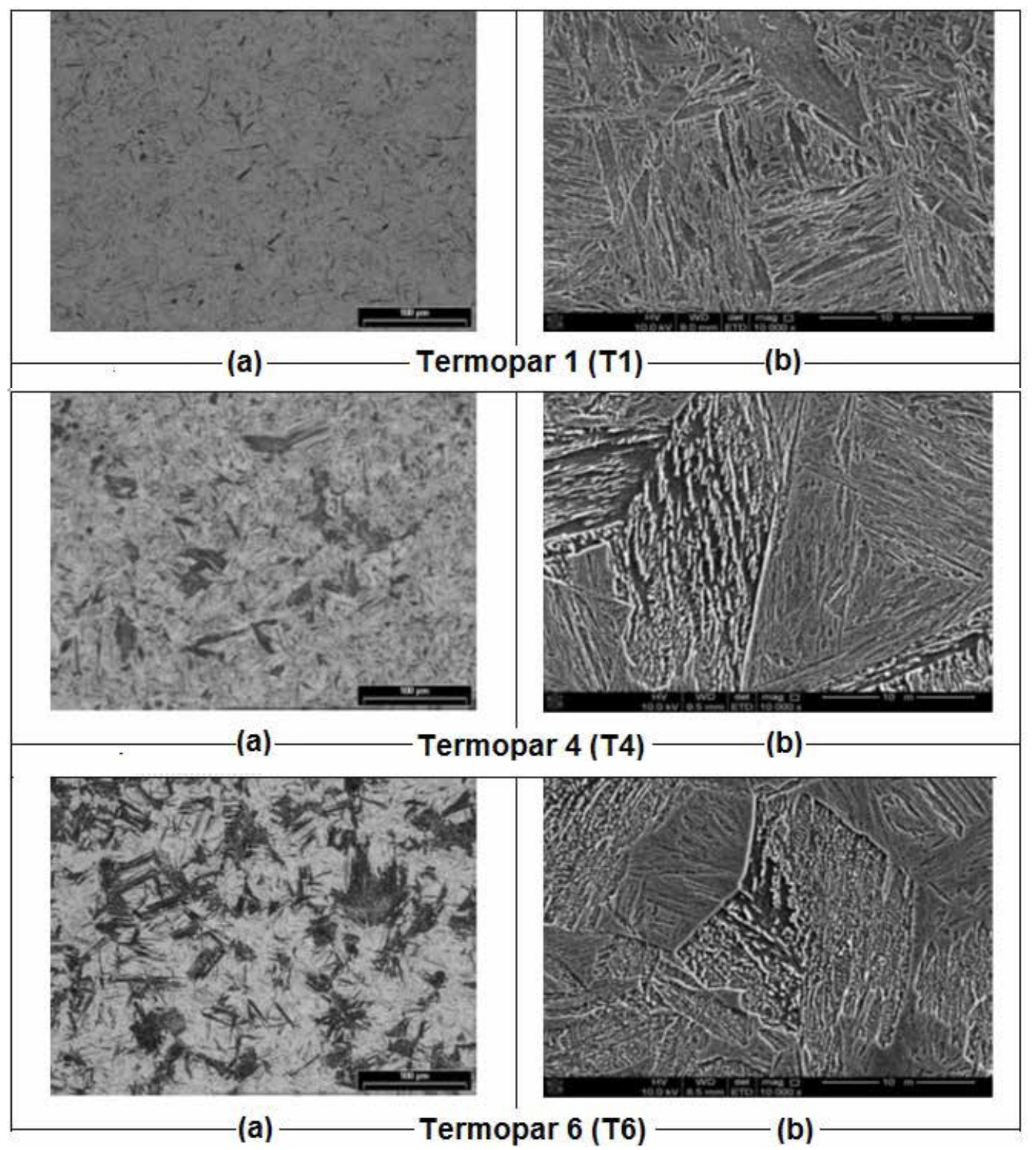

Fonte: dos autores, 2014 


\section{CONCLUSÃO}

Neste trabalho foi avaliado o efeito da velocidade de resfriamento sobre a transformação da austenita em um aço AISI 4340, estando os resultados sumarizados a seguir.

1. As velocidades de resfriamento desempenham tanto qualitativa, como quantitativamente, um importante papel sobre os produtos da transformação da austenita.

2. Em concordância com as transformações previstas pelo diagrama de transformação durante o resfriamento contínuo do aço AISI 4340, as velocidades de resfriamento atingidas pela austenita, neste estudo, propiciaram somente a formação dos microconstituintes bainita e martensita.

3. As frações volumétricas de martensita, que foram obtidas experimentalmente, apresentaram boa concordância com aquelas previstas pela equação cinética de Koistinen e Marburger.

4. A dureza da bainita foi influenciada pela velocidade de resfriamento, ou seja, menores velocidades de resfriamento implicaram em uma menor dureza para esse microconstituinte, podendo esse resultado ser atribuído à formação de maior quantidade de bainita superior em relação à bainita inferior.

5. Diferentemente da bainita, a dureza da martensita não foi praticamente afetada pela mudança na velocidade de resfriamento, variando muito pouco em torno de um valor médio. Este resultado está coerente, pois a dureza da martensita depende, principalmente, do teor de carbono do aço.

6. Os resultados deste estudo podem ser usados com o objetivo de prever as microestruturas a serem obtidas em processos que envolvam aquecimento e resfriamento contínuo, conforme ocorre, por exemplo, em uma eventual soldagem do aço AISI-4340.

7. A metodologia proposta pode ser estendida ao estudo das transformações que ocorrem durante o resfriamento contínuo de outros tipos de aços, a partir de uma temperatura considerada crítica, da mesma forma como para as ligas não ferrosas, com o objetivo de obter informações e parâmetros para fins de controle microestrutural e, consequentemente, das suas propriedades. 


\section{REFERÊNCIAS}

1 HAZAN, E.; SADIA, Y.; GELBSTEIN, Y. Characterization of AISI 4340 corrosion products using Raman Spectroscopy. Corrosion Science, v. 74, p. 414-418, 2013.

2 YI, J.; GHARGHOURI, M.; BOCHERC, P.; MEDRAJ, M. Distortion and residual stress measurements of induction hardened AISI 4340 discs. Materials Chemistry and Physics, v. 142, p. 248-258, 2013.

3 WOEI-SHYAN, L.; TZAY-TIAN, S. Mechanical properties and microstructural features of AISI 4340 high-strength alloy steel under quenched and tempered conditions. Journal of Materials Processing Technology, v. 87, p. 198-206, 1999.

4 ABBASZADEH, K.; SAGHAFIAN, H.; KHEIRANDISH, S. Effect of bainite morphology on mechanical properties of the mixed bainite-martensite microstructure in D6AC steel. Journal of Materials Science and Technology, v. 28(4), p. 336-342, 2012.

5 SINGH, S. B.; BHADESHIA, H. K. D. H. Estimation of bainite plate-thickness in low-alloy steels. Materials Science and Engineering A, v. 245, p. 72-79, 1998.

6 PORTER D. A.; EASTERLING, K. E. Phase transformations in metals and alloys. $2^{\text {th }}$ ed. London, UK: Chapman \& Hall, 1991.

7 YAN, W.; XIAO, N.; CHEN, Y.; LI, D. Phase-field modeling of Widmanstätten ferrite formation during isothermal transformation in low carbon steels. Computational Materials Science, v. 81, p. 503-509, 2014.

8 ABNT - Associação Brasileira de Normas Técnicas. Aço - Determinação da Temperabilidade Jominy, NBR 6339, 1989.

9 KOISTINEN, D. P.; MARBURGER, R. E. A general equation prescribing the extent of the austenitemartensite transformation in pure iron-carbon alloys and plain carbon steels. Acta Metallurgica, v. 7 (1), p. 59-60, 1959. 